\title{
Junior Primary Music Education in Nigeria
}

\author{
Young-Sook Onyiuke \\ Babcock University, Ilishan Remo, Ogun State, Nigeria
}

\begin{abstract}
Modern day trend and challenges require that all children be given the opportunity to develop their musical abilities to the full. Music education is significant in achieving this. In Nigeria, music education in primary school, junior primary section in particular, does not effectively realise this purpose in most public primary schools across the country. This lapse is as a result of shortage of music experts to teach the subject, unavailability of user-friendly subject syllabi, and most importantly, ineffective instructional lesson materials. The aim of this study is to provide some useful instructional material and guide on the basic aspects of teaching and learning process for music teachers in junior primary schools in Nigeria. The main contribution of this study is the presentation of a lesson series with complete work-out lessons for early formal music education and recommendation for all sectors involved in primary music education in Nigeria.
\end{abstract}

Keywords: primary education, primary music education, music education in Nigeria

\section{Importance of Childhood Music Education}

Every human being is born with a certain level of musical potential. The most powerful neural networks and behavioural attitudes are developed during childhood. Therefore, childhood music education plays an essential role in developing and consolidating this given potential (Gruhn, 2005, p. 99). Since the beginning of time music has been part of man and the everyday life of all communities and cultures. Bergethan and Boardman (as cited in Schoeman, 1993) noted that "from the most primitive to the most sophisticated of cultures, music has been central to every ritual. Every significant event in man's personal life has its accompanying musical expression. The very existence of music and the importance thereof in everyday life necessitates a rightful place for the subject in the school programme."

The role of music education is to equip children with the necessary knowledge and skills to adapt to this environment. Technological development also results in people having increasingly more free time on their hands and many people will turn to music for recreation and the enrichment of their lives. Education implies that every member of society should have avenues open to him/her to improve his knowledge and skills and to contribute to his/her quality of life. Music can supply such an avenue. In music, each individual can find his/her own expression and create his/her own interpretation. For this reason, a child's preparation for life will be incomplete if his/her education in music is neglected.

All children should be given the opportunity to develop their musical abilities to the full. The inclusion of music in an education programme is significant in fulfilling the requirements of the so-called "whole-child-education" (as cited in Campbell, 1995). Music contributes to the physical, intellectual, emotional,

Young-Sook Onyiuke, associate professor, Department of Music \& Creative Arts, School of Education and Humanities, Babcock University. 
aesthetic, and social development of the child. Music provides enjoyment and the opportunity to express feelings, to relieve physical tension, and to bring emotional release. Learning through music can also promote and add enjoyment to the learning of skills necessary for the understanding of all the other school subjects. Zoltan Kodaly, the well-known Hungarian composer and music educator said the following (as cited in Campbell, 1995), "Music education contributes to the many-sided capabilities of a child, affecting not only specifically musical aptitudes but his general hearing, his ability to concentrate, his conditional reflexes, his emotional horizon and his physical culture" (p. 8). Yick-ming expressed, "Music in education is education in life" (p. 8). She further noted that children need every exposure to music, and lack of financial resources should not be used as an excuse for omitting music education from school programme. Therefore, we, music educators, continue to plead "music education right from childhood, music for everyone, and music for our everyday life."

The major purpose of any music programme for the primary school is to provide opportunities for children to explore and enjoy music, to obtain basic musical skills, and to develop readiness and willingness for further learning of and participation in music activities. According to Carl Orff (as cited in Campbell, 1995):

It is at primary school age that the imagination must be stimulated; and opportunities for emotional development, which contain experience of the ability to feel, and the power to control the expression of that feeling, must also be provided. Everything that a child of this age experiences, everything in him that has been awakened and nurtured is a determining factor for the whole of his life. (p. 7)

An issue for music educators worldwide is how a diversity of musical experiences can form a coherent music education, enabling young people to develop musically and personally (Hallam, 2011, p. 155). The success of any educational programme depends on the teachers. When there are no well-prepared teachers to implement a well-designed curriculum the programme dies.

Music can assist each child in the realization of his physical, social, emotional aesthetic, and intellectual potentialities. Music, therefore, provides an opportunity for the child to do this in creative ways and it helps in the development of a complete and balanced individual that will actively participate in the activities of the community. Therefore, having this mind, following lesson series has been prepared for music program in the junior primary school level in Nigeria.

\section{Suggested Music Lesson Series for Junior Primary School in Nigeria}

Why Music?

1. Music makes you happy.

2. Music helps develop your mind.

3. Music help develop your body.

4. Music gives you something to do.

5. Music can be shared with others.

\section{What? How?}

\section{$\bigcirc$ Learn about the elements of music $-\circ$ Singing—sing songs with:}

Pitch: high-low good breathing;

Duration: rhythm (long-short) good diction;

Dynamics: colour of music (loud-soft) good phrasing;

Tone-colour: mood, voices, and instruments good tone. 
Tone structure: combination of sounds $\circ$ Dancing-learn about rhythm, beat, and tempo

oLearn about music through—-through: walking, matching;

Performing: singing running;

dancing skipping, galloping;

playing waltzing.

Appraising: listening $\circ$ Playing—by using instruments, such as:

Appreciating laps, voice, and traditional instruments;

Composing: improvising new home-made simple instruments

Songs $\circ$ Listening—simple and short melodies of:

dances environmental sounds;

instrumental music vocal music; instrumental music;

music for movement.

\section{Aims}

\section{Long term/short term}

$\circ$ To develop a love of music. $\circ$ Development of perceptual-motor skills:

$\circ$ To obtain musical literacy, kinesthetic perception, body awareness, balance,

- To provide opportunities to develop music laterality, directionality, spatial awareness, abilities, positionin space, and co-ordination.

oTo stimulate an interest in activeo Development of visual-auditory skills:

participation, memory, discrimination, and foreground-background.

$\circ$ To become aware of one's own and other form constancy, form observation, analysis, culture ssynthesis, and conceptualising.

\section{Objectives}

\section{oDevelopment of technical skills:}

Performing: Singing — voicetraining, enlargement of song repertoire;

Dancing - knowledge of different movements and interpretation of music;

Playing - handling of instruments and group playing.

Composing: Creating new rhythms and melodies;

Creating new combinations of movement;

Improvising rhythms on instruments;

Improvising melodies on melodic instruments;

Creating instrumental accompaniment.

Appraising: Discipline of listening attentively;

Recognising, identifying, and classifying sounds.

\section{DDevelopment of aural skills:}

To sing on pitch, to move, to the rhythm of music, to make music in a group, to evaluate performance, and to create original musical ideas.

oDevelopment of skills in rudiment of music.

\section{Core Content}

\section{Concepts}


oDuration: Rhythm—-long/short, sound/silence; Beat—duple/triple time; Tempo—fast/slow, getting faster/slower.

○Pitch: High/low, going up/down, the same;

oIntervals: d-r; d-m; d-s; d-d'; m-f; et al.;

oDynamics: Loud/soft, getting louder/softer;

oTone colour: Environmental sound; music/noise/silence; Voices—speaking/singing, male/female/children;

Instruments—percussion; Mood—happy/sad, heavy/light.

oTone structure: Melody—rhythm/pitch; Form—repetition/contrasts.

\section{Activities.}

$\circ$ Performing_-Singing

-Notation: Duration Dynamics: musical terms and signs to indicate loud, soft, getting:

Half note (minim) louder, becoming softer.

- Quarter note (crochet) -Tonics ol-fa and hand signs (as shown below) to indicate definite

-) Eighthnote (quaver) pitch. It is not only present a "visualization of tonal relationships,

- Half note rest, but also appear to establish memory of pitch patterns more securely

Quarter rest than if they were not used" (Choksy, 1981). They also establish a Kinaes thetic association with the notes. Once, the children become acquainted with definite pitch notation, the relatives ol-fa signs are discarded.

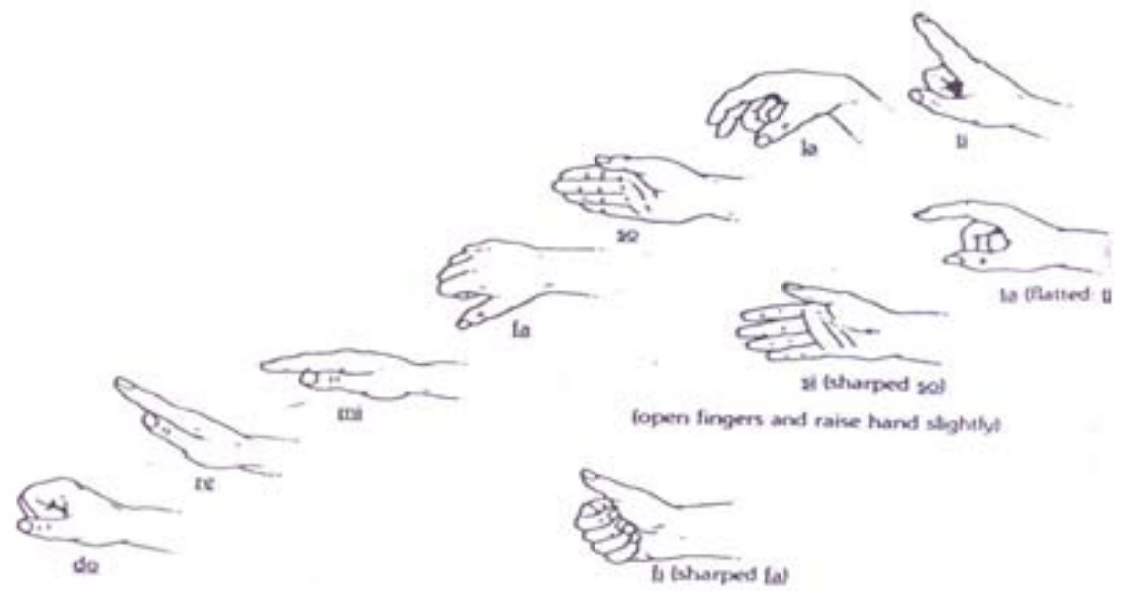

Figure 1. Curwin's hand signs. (Source: Curwin's hand signs, modified by Kodóly [as cited in Choksy, 1981])

○Performing-Dancing

Duration: Pitch:

Rhythm—walk • high/middle/low movement run .) 
skip . light/heavy, happy/sad

gallop . - $\square$ Tone structure: repetition and contrast

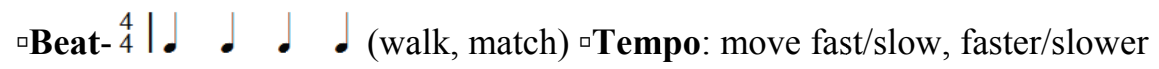

$\frac{3}{4} \uparrow \uparrow$ (waltz, swing)

$\circ$ Performing—Playing instruments

口Body percussion: ${ }^{\mathrm{P} e r c u s s i o n ~ i n s t r u m e n t s: ~}$

echo-clapping;

play on the beat;

tap on the beat;

play rhythm patterns;

clap the rhythm.

$\circ$ Composing $\circ$ Appraising

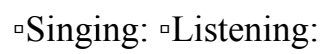

Improvising songs;

environmental sounds;

Create new melodies for existing ward male, female, and children'svoices;

-Dancing: melodic and percussion instruments;

improvise rhythmic movement.

-Appraising:

dramatise stories, songs;

underst and how musicis organised.

口Playing:

Evaluate the music of others;

Improvise accompaniments to songs and dances;

Evaluate own music.

Create instrumental music.

\section{Cross-Curricular Integration}

Topics for singing, dancing, playing, and listening can be chosen from the school subjects, for example:

$\circ$ Religious studies: the Birth of Christ; the creation.

o Physical education: movement development; physical development; social-emotional development; and cognitive development.

$\circ$ Health education: hygiene; safety rules; and traffic rules.

$\circ$ Mathematics: counting and vocabulary.

$\circ$ Languages: vocabulary; diction; and phrasing.

\section{Didactic Guidelines}

Good teaching should be used at all times. 
Musical sounds are at the centre of every lesson;

All children should take an active part in lessons.

O Singing

Teaching of songs:

Compass: Care should be taken to use songs with a limited range to match young children's singing abilities.

Matching pitch: The emphasis here must be on attentive listening, to enable correct imitation of singing tones.

Developing good tone quality: Good breathing habits should be stressed to support the singing voice. Note that the shoulders should not be raised or slumped. Make use of all the lung spaces.

Improvising diction: Stress consonants at the beginning and at the ending of words, so that words can be clearly understood. Demonstrate poor diction (lazy lips and tongue) and good diction-exaggerate consonants, lips, and tongue exercise, such as wa-wa, la-la-la, non-non or "No jaw tension exercise" as Mancusi and Paulk (2012, p. 20) suggested: la-bay-da-bay-nee-po-too-la-bay, et al..

Singing with expression: Control of the voice is important. Make pupils aware of the blending of voices and undesirability of voices that standout. Give special attention to the dynamic levels of a song.

Tempo: Choose a comfortable tempo to ensure clarity of diction and tone.

\section{Teaching Songs by Rote}

The length of songs and the use of repetition will determine the teaching method. Longer songs might need subdivision in order to help children remember them. Repetition within songs may be pointed out to make learning more efficient.

Schoeman (1993, pp. 7-8) suggested three ways of organising the learning of a song by rote:

1. Absorption: The song is sung by the teacher (or on tape) and is repeated by the children until they know it by heart. This is an effective manner of teaching short songs.

2. Segmentation: The song is divided into sections to facilitate the learning thereof.

3. Segmentation and absorption: This method is effective in teaching songs with choruses, where the chorus part may be taught first. Where more than one verse occurs, the words of some of the verses may be omitted and used at a later stage, to prevent children from getting bored with the song.

Note that the song should always be presented "as a whole" at first (Leonhard \& House, 1972, p. 287). Explain the words of the song if necessary, e.g., if a foreign language or foreign words are used. Two folk songs have been presented here in staff notation, although many music teachers in Nigeria are familiar with the sol-fa notation system, this study encourages staff notation. The Nigerian folk song "udala $\mathrm{m}$ too" as illustrated in Appendix II uses locally accessible indigenous instruments and Appendix I is an example of pentatonic scale music piece from Korea.

o Performing

Movement. $\circ$ Ensure that enough space is available for the movement to be carried out.

o Pupils should wait for a sign to start movement.

○ Before any movements are commenced, the pupils should be able to hear the beat clearly.

- All movements should have a definite beginning and ending. Encourage pupils to finish movement neatly. Even the simplest movement should be performed with accuracy and control. 
○ The teacher may use recorded music, class room instruments as a stimulus for movement activities.

Playing instruments. $\odot$ Write different rhythmic pattern on the board and demonstrate the rhythmic pattern.

$\circ$ Attentive listening is again essential in order to play the rhythm and/or beat clearly, to start and end playing together.

- To avoid chaos during an instrumental session, pupils should be instructed not to play without being instructed to do so. Attention should be paid to the leader, conductor or teacher. Arrange pupils in such a manner that the teacher (conductor) is clearly visible to everyone. Correct playing techniques should be taught from the beginning.

..

Q Composing

- Composing could take place as a group activity. Children can work together as a class or in smaller groups. This facilitates the task of the teacher in giving support.

$\circ$ Let the children play with sound in a music corner. Encourage them to bring interesting sounds to school, listen to sounds, talk about, and compare them. Any home-made or classroom instruments, the voice or other sound source may be used. This may be done as a starting point to stimulate creativity.

- During a composing lesson,the teacher has to lead and support activities to some extent:

(1) A stimulus or idea may be suggested by the teacher or the pupils, followed by a discussion;

(2) Observation, listening, and experimentation with ideas are conducted;

(3) At this point, intervention by the teacher may be necessary to give extra help;

(4) The drawing together of ideas in the performance of thecomposed musicpiece.

○ Appraising

- All learning processes are dependent on effective listening. Music always involves listening and provide excellent opportunities for the development of listening skills. The benefits of this development apply to learning across the curriculum.

$\circ$ Pupils should be introduced to the discipline of attentive listening procedures. A helpful hint is to close the eyes when listening at first, before any actions are carried out.

- Music examples should be very short during the first school year (approximately 20-40 seconds per extract), as the attention span of children is still very short. The time-span of listening activities can gradually be lengthened.

o General teaching strategies

$\circ$ Teach in many small steps rather than in one big step.

$\circ$ Be alert for signs of fatigue and boredom and deal with them quickly by changing to a counter acting activity.

o Teaching media

Media comprises all the resources used by the teacher to accomplish teaching aims and objectives. Media may be classified under two categories: (1) media for teaching (used by the teacher); and (2) media for learning (used by pupils). A variety of different media should be used in the teaching situation and should be selected purposefully. Media could be intrinsic (the teacher self-use of the voice, mime, and body language) or extrinsic (auditory, visual, and audio-visual). Examples of extrinsic media are: Non-technological media, such as hand book, writing-board, pictures, flash-cards, graphic presentation, models etc.; and technological media, such as overhead projector, radio, compact disc (CD) player, film projector, television, slide projector, computer, et al.. 
口 Differentiation

$\circ$ Lessons should be constructed in such way that it makes provision for all pupils. Core content may be adapted to suit individual preferences.

$\circ$ All pupils should be encouraged to develop to their full potential according to their own abilities and interests. Ensure that all pupils participate in activities.

o Cross-curricular integration

- Learning through music can expand the pupil's interest and knowledge in particular aspect of the curriculum.

- Music can flow from the overall curriculum. The development of languages skills in particular takes place in all aspects of a music programme.

a Assessment

- Every lesson unit should be evaluated at the end to determine whether the expected standard of skills were reached. The teacher will then be able to do remedial work or change method if necessary.

$\circ$ The knowledge of pupils should be determined at the beginning and at the end of a lesson unit to ascertain the success of the teaching. During the course of the lesson, the pupils' progress should be monitored to be able to consider the didactic efficiency.

\section{Recommendations for Improvement of Music Education in Nigerian Primary Schools}

Based on the survey of the literature and the author's investigation in the field of junior primary music education in Nigeria, the following recommendations have been proffered for the development of music education inpublic primary schools in Nigeria.

\section{Government Concern}

The government should make the music programme a fully-fledged subject in the primary school curriculum. It should not be taken as an alternative to any other subject in the school curriculum.

Music teachers should be posted by the government to primary schools to ensure that music is being taught by music teachers trained for that purpose.

The government should equip the schools with musical instruments to enhance the effective teaching and learning.

Government should make sure that when reviewing the primary school curriculum, music specialist should be involved to make their input.

\section{School Administrator, Teachers, Parents, and Children Concern}

Consider holding an orientation for parents and guardians as well as other potential advocates at the beginning of each year of the study.

Periodic competitions should be organized, so as encourage performances, interaction, and further works and discover talents.

Mass music experiencing activities, in which all pupils are enable to express themselves freely, should be provided in the daily school program.

The use of staff notation by music teachers (non-specialists) in Nigeria is recommended.

Pupils with exceptional potential in music should be provided with opportunities of sponsorship.

Teachers should adopt an individual approach in the process of teaching bearing in mind that all children differ in intelligence, aptitude, interests, temperament, age and social, and religious backgrounds. 
Parents should provide children with the opportunity to experience music at home: listening of music, singing, and playing home-made simple musical instrument.

The activities provided for a child should include a substantial amount of singing experience, preferably together with his/her parents, an opportunity to explore a wide range of the environment in which he/she lives.

Parents should provide children with the opportunity of watching performances at concert or festivals in order to gain musical experience.

\section{Tertiary Institution Concern}

Among the students of the tertiary institution are the future teachers of the primary schools. It is, therefore, necessary to consider them in the study of primary school music education.

Department of Music in Universities and College of Education in Nigeria should be encouraged to conduct regular workshops in which their own students of music, as well as primary teacher education students and practicing teachers must participate in.

Workshops or seminars on simple and homemade musical instrument should be available (Onyiuke, 1991, pp. 50-55).

\section{Financial Support Concern}

- Support from the Nigerian government:

A reasonable provision should be made for music education in the national budget.

The Nigerian government should provide adequate funds for infrastructure, equipment, musical instruments, qualified music teaches, and other facilities that will enhance music education at all levels.

- School organization:

Apart from the government funds, the school organization could appeal to the stake holders, individuals, and parents for their contributions as well as companies, both nationally and internationally.

\section{Conclusions}

This study is an attempt to emphasize the importance of music education for early age of children. It is also aimed at presenting a music lesson series, particularly to the public junior primary schools in Nigeria. In recent times, most private primary schools in Nigeria are well planned, equipped, and qualified with music teachers to handle music classes and regular performances within school and elsewhere, but this is not the case in public primary schools. Music education in this sector has merely improved since the first time the author investigated this matter 25 years ago. Although music is included in the primary school syllabus, it is often neglected. Government's written commitment to ensuring that children receive music education has not been adequately fulfilled to date.

The author also stressed that the most important fact that experience in music can help the child to understand different aspect of his or her own culture and that of others. Finally, recommendations for all sectors involved in primary music education in Nigerian schools have been made. Certainly, the inculcation of early childhood music education is one way of equipping our young generation to become musically talented with bright prospect in the future.

\section{References}

Campbell, M. R. (1995). Interdisciplinary projects in music. Music Educators Journal, 82(2), 37-44.

Choksy, L. (1981). The Kodóly method. Englewood Cliffs, N.J.: Prentice-Hall. 
Gruhn, W. (2005). Children need music. International Journal of Music Education (Showcase), 23(2), 99-101.

Hallam, R. (2011). Effective partnership working in music education: Principles and practice. International Journal of Music Education (Practice), 29(2), 155-171.

Leonhard, C., \& House, R. W. (1972). Foundations and principles of music education (2nd ed.). New York: McGraw-Hill.

Mancusi, R., \& Paulk, K.(2012). Song anthology. N.J.: Silver Burdett Ginn.

Onyiuke, Y. S. (1991). Teaching instrumental music as a source of aesthetic education for children: A survey of views and implications for Nigeria (M.A. thesis, University of Nigeria, Nsukka).

Onyiuke, Y. S. (2011). Literature, language and music education of the child. Journal of Music and Aesthetics (JOMA), 1(2), 96-100.

Schoeman, L. (1993). A teacher training programme for junior primary music education. Adaptable for Botswana and South Africa-A multicultural approach (PhD dissertation, University of Pretoria).

Yick-ming, R. W. (2005). Music in education is education for life. International Journal of Music Education (Showcase), 23(2), 107-110.

\section{Appendix I}

Arirang

Folk song from South Korea

Arranged by Young-Sook Onyiuke

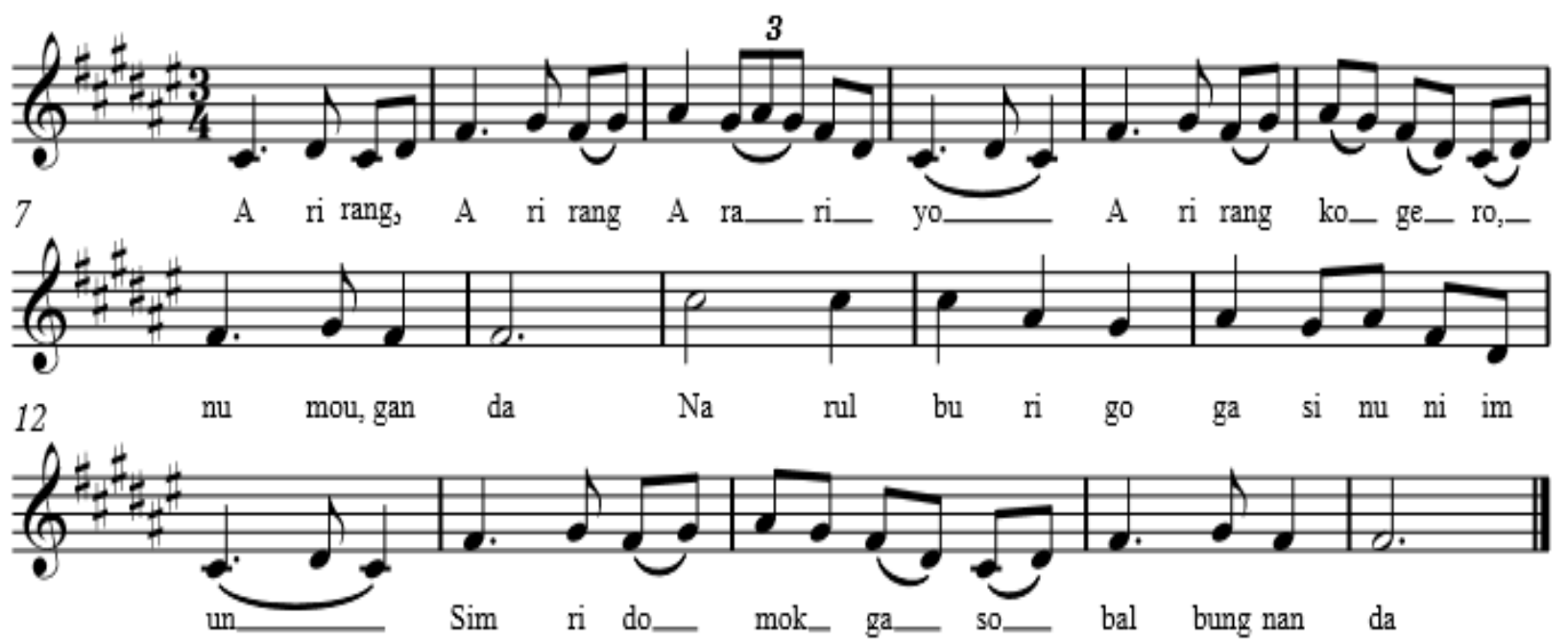

Arirang, Arirang, Arariyo

Arirang, pass through the Arirang hill

I'll follow you follow you go there , Here you wait for me Arariyo 


\section{Appendix II}

Udala M Too

Folk Song from the Igbo Tribe of Nigeria

Arranged by Alvan-Ikoku Nwamara
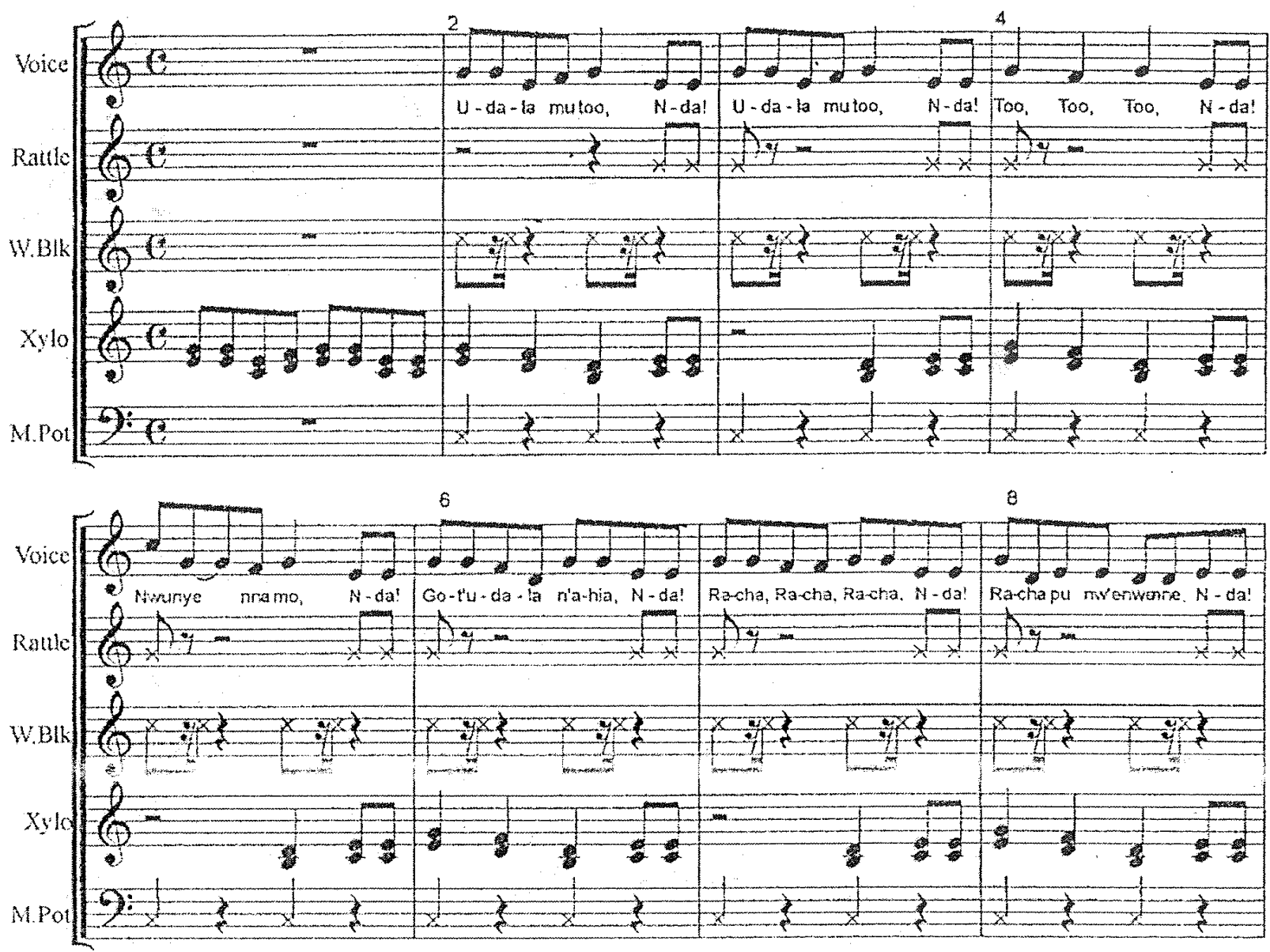

10

12

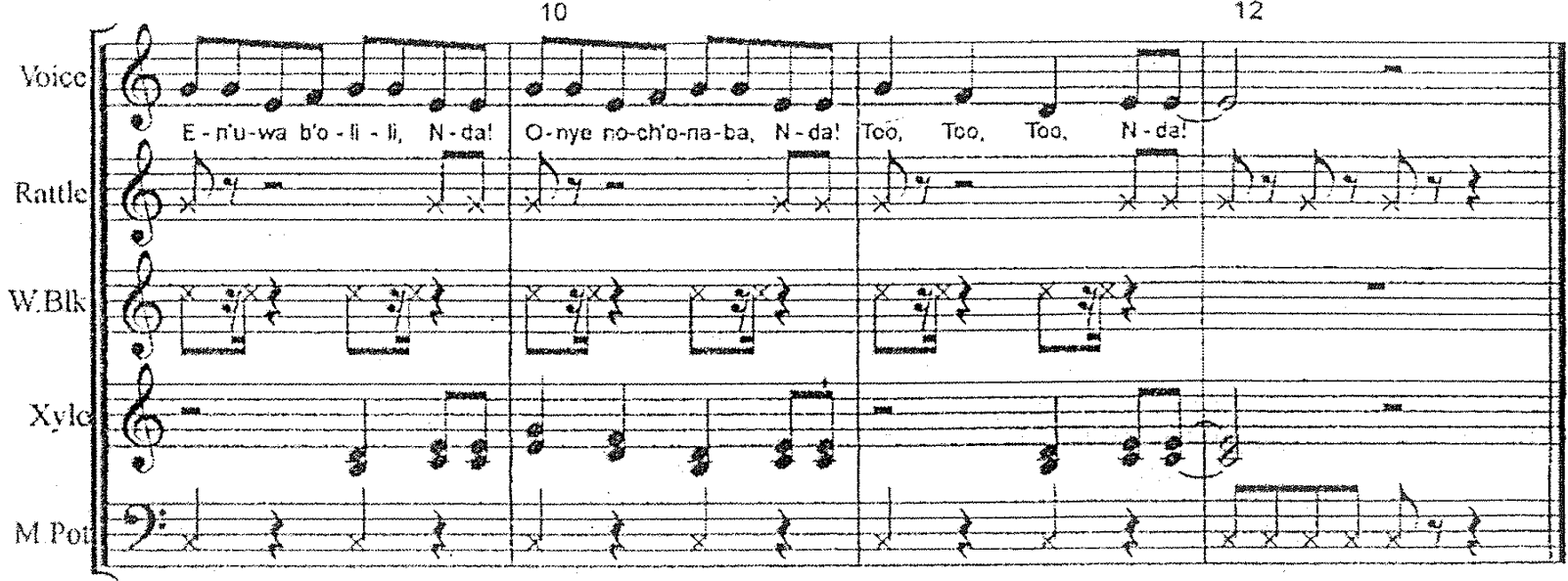

My apple fruit grow, $N d a$, my apple fruit grow $N d a$, grow grow grow $N d a$,

My step mother $N d a$, bought an apple fruit, $N d a$, lick lick lick, $N d a$,

Leaving motherless, the world is a stage, $N d a$, we ome and we go, $N d a$. 